\title{
What made Canada become a country with the highest incidence of inflammatory bowel disease: Could sucralose be the culprit?
}

\author{
Xiaofa Qin MD PhD
}

$I^{\text {n }}$ nflammatory bowel disease (IBD) (which includes both ulcerative colitis and Crohn's disease [CD]) emerged and dramatically increased in the past century (1). Early studies revealed that IBD was most prevalent in countries such as the United Kingdom, the United States and those in northern Europe (1). Compared with these countries, the prevalence of IBD in Canada was much lower. This was demonstrated in early epidemiological studies conducted in Canada. According to a review by Mayberry and Rhodes (2), a study published in 1972 reported the incidence and prevalence of CD in Sherbrooke, Quebec, at only 0.7 and 6.3 per 100,000 population, respectively, which were much lower than countries such as the United Kingdom, the United States, Sweden, Denmark, and even Israel and New Zealand at the same time or even decades earlier. However, studies in recent years have suddenly found that Canada has become a country with the highest incidence of IBD (3). For example, the prevalence of CD in Alberta in 1981 was only 44 per 100,000 population (4), compared with 91 per 100,000 in Olmsted County, Minnesota (USA) on January 1, 1980 (5). However, the prevalence of CD in Alberta increased to 283 per 100,000 on July 1, 2000 (3), compared with 174 per 100,000 in Olmsted County in January 1, 2001 (6). It would be valuable to know what caused the dramatic increase of IBD in Canada because it may provide critical information regarding its etiology.

A decade ago, a series of accidental findings made me suspect that the impaired inactivation of digestive proteases due to the inhibition of gut bacteria by dietary chemicals, such as saccharin, play a causative role in IBD as a result of the accelerated degradation of the mucous layer and underlying endothelium (7). It provided an explanation for many puzzles in IBD such as the dramatic increase of IBD in the 1950s and 1960s, and its levelling off since the latter part of the 1970s, as observed in many western countries including Canada $(4,7)$. However, this hypothesis was challenged by the failure to provide an explanation for the recent high incidence of IBD in Canada, which had adopted more stringent standards for the use of saccharin than most other western countries after the finding of carcinogenic effects of saccharin on the bladders of experimental animals in 1977.

If not saccharin, then what caused the remarkable increase of IBD in Canada? I suggest that sucralose may be the culprit. Sucralose is a new, non-nutrient, high-intensity sweetener that has many superior properties. It is approximately 600 times sweeter than sucrose (thus two times sweeter than saccharin). Similar to saccharin, sucralose is heat and $\mathrm{pH}$ stable, but without the bitter aftertaste (8). In 1991, Canada was the first country to approve the use of sucralose, and it was allowed to be used as a tabletop sweetener in breakfast cereals, beverages, desserts, toppings, fillings, chewing gum, breath mints, fruit spreads, salad dressings, confectionary, bakery products, processed fruits and vegetables, alcoholic beverages, puddings and table syrups (8). Interestingly, the study by Wrobel et al (9) reported that the incidence of pediatric IBD in Southern Alberta was 2.3 (per 100,000 population) between 1983 and 1987, 2.5 between 1988 and 1992, 5.0 between 1993 and 1998, and 6.5 between 1999 and 2005 (9), indicating a dramatic increase in the early 1990s. Could sucralose cause the increase of IBD in Canada? How?

Similar to saccharin, sucralose can also exert potent inhibition of gut bacteria (10). However, it may have a more pronounced effect on gut bacteria than saccharin in that approximately $65 \%$ to $95 \%$ of sucralose is excreted through the feces unchanged (10), while a large proportion of saccharin is absorbed and eliminated through urine; the acceptable daily intake of sucralose is $15 \mathrm{mg} / \mathrm{kg}$, but only $5 \mathrm{mg} / \mathrm{kg}$ for saccharin. As I suggested a decade ago, regarding the possible risk of saccharin on IBD (7), sucralose may have a similar but stronger impact on gut bacteria, digestive protease inactivation and gut barrier function. This may provide a possible explanation for the more pronounced high incidence of IBD observed in Canada. The use of sucralose is soaring, and is now being used in thousands of food products (10). Therefore, it would be worthwhile to investigate whether possible links between sucralose intake and IBD exist, before it is too late.

\section{REFERENCES}

1. Binder V. Epidemiology of IBD during the twentieth century: An integrated view. Best Pract Res Clin Gastroenterol 2004;18:463-79.

2. Mayberry JF, Rhodes J. Epidemiological aspects of Crohn's disease: A review of the literature. Gut 1984:25:886-99.

3. Bernstein CN, Wajda A, Svenson LW, et al. The epidemiology of inflammatory bowel disease in Canada: A population-based study. Am J Gastroenterol 2006;101:1559-68.

4. Pinchbeck BR, Kirdeikis J, Thomson AB. Inflammatory bowel disease in northern Alberta. An epidemiologic study. J Clin Gastroenterol 1988;10:505-15.

5. Gollop JH, Phillips SF, Melton LJ III, Zinsmeister AR. Epidemiologic aspects of Crohn's disease: A population based study in Olmsted County, Minnesota, 1943-1982. Gut 1988;29:49-56.

6. Loftus CG, Loftus EV Jr, Harmsen WS, et al. Update on the incidence and prevalence of Crohn's disease and ulcerative colitis in Olmsted County, Minnesota, 1940-2000. Inflamm Bowel Dis 2007;13:254-61.

7. Qin XF. Impaired inactivation of digestive proteases by deconjugated bilirubin: The possible mechanism for inflammatory bowel disease. Med Hypotheses 2002;59:159-63.

8. Knight I. The development and applications of sucralose, a new high-intensity sweetener. Can J Physiol Pharmacol 1994;72:435-9.

9. Wrobel I, Butzner J, Nguyen N, Withers G, Nelson K. Epidemiology of pediatric IBD in a population-based cohort in southern Alberta, Canada (1983-2005). J Pediatr Gastroenterol Nutr 2006;43:S54-5.

10. Abou-Donia MB, El-Masry EM, Abdel-Rahman AA, McLendon RE, Schiffman SS. Splenda alters gut microflora and increases intestinal p-glycoprotein and cytochrome $\mathrm{p}-450$ in male rats. J Toxicol Environ Health A 2008;71:1415-29.

Department of Surgery, University of Medicine and Dentistry of New Jersey - New Jersey Medical School, Newark, New Jersey, USA

Correspondence: Dr Xiaofa Qin, Department of Surgery, University of Medicine and Dentistry of New Jersey - New Jersey Medical School,

Newark, 185 South Orange Avenue, Newark, New Jersey 07103, USA. Telephone 973-972-2896, fax 973-972-6803,

e-mail qinxi@umdnj.edu

Received for publication May 5, 2011. Accepted May 13, 2011 


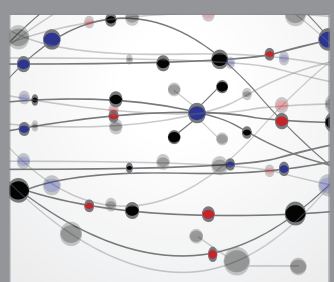

The Scientific World Journal
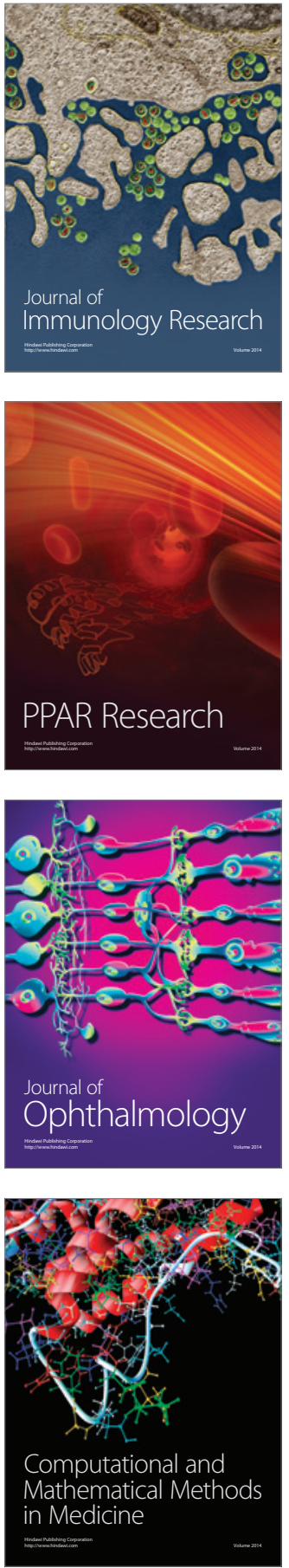

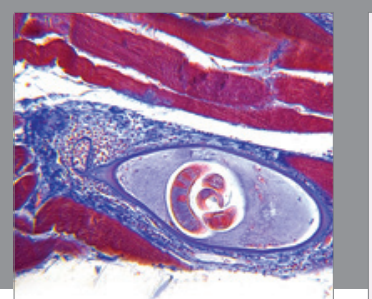

Gastroenterology Research and Practice

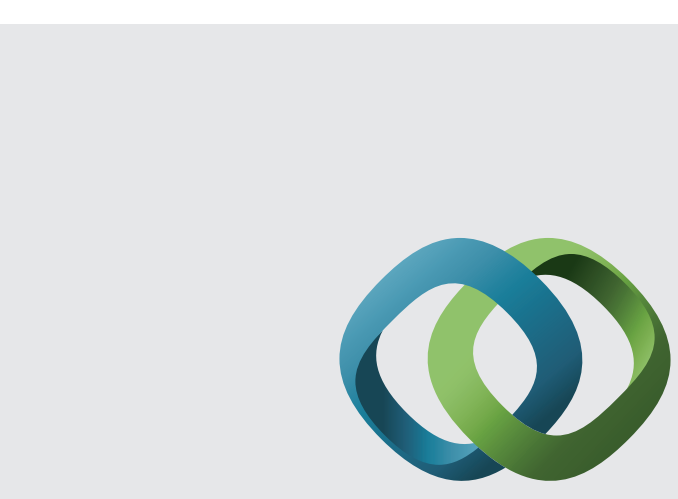

\section{Hindawi}

Submit your manuscripts at

http://www.hindawi.com
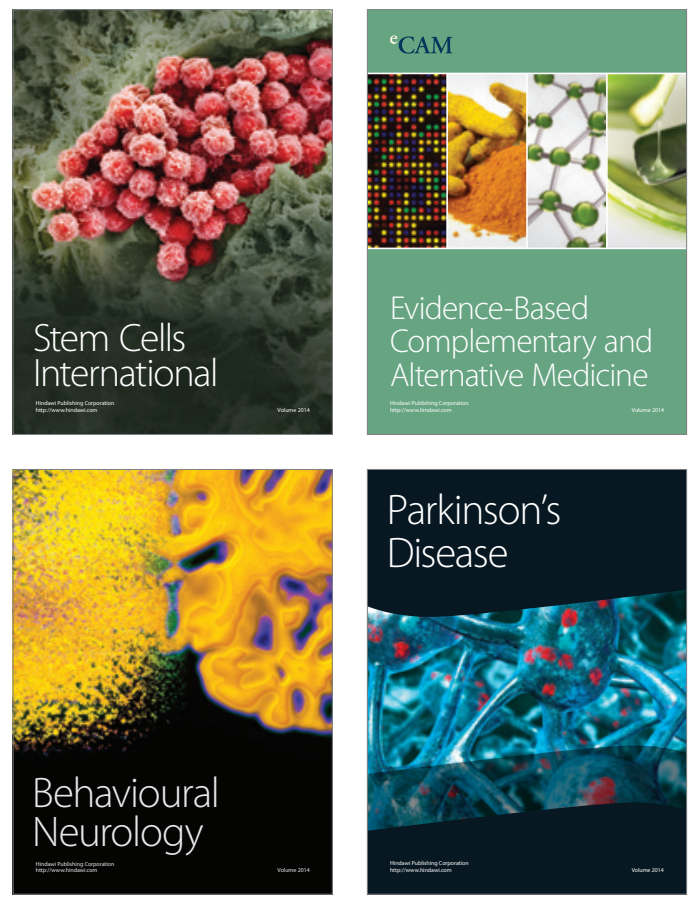
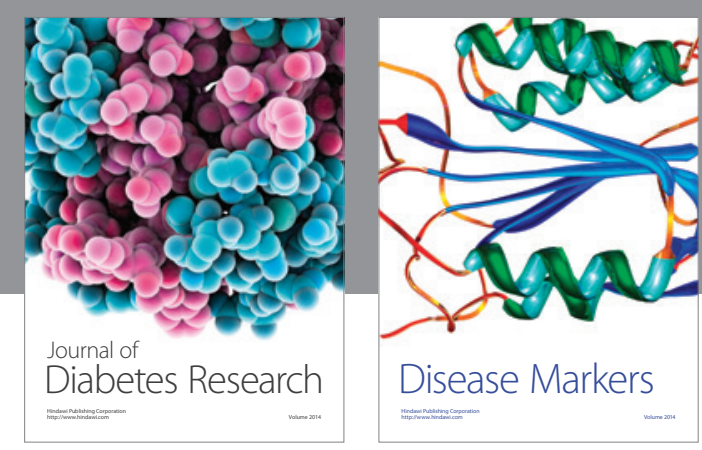

Disease Markers
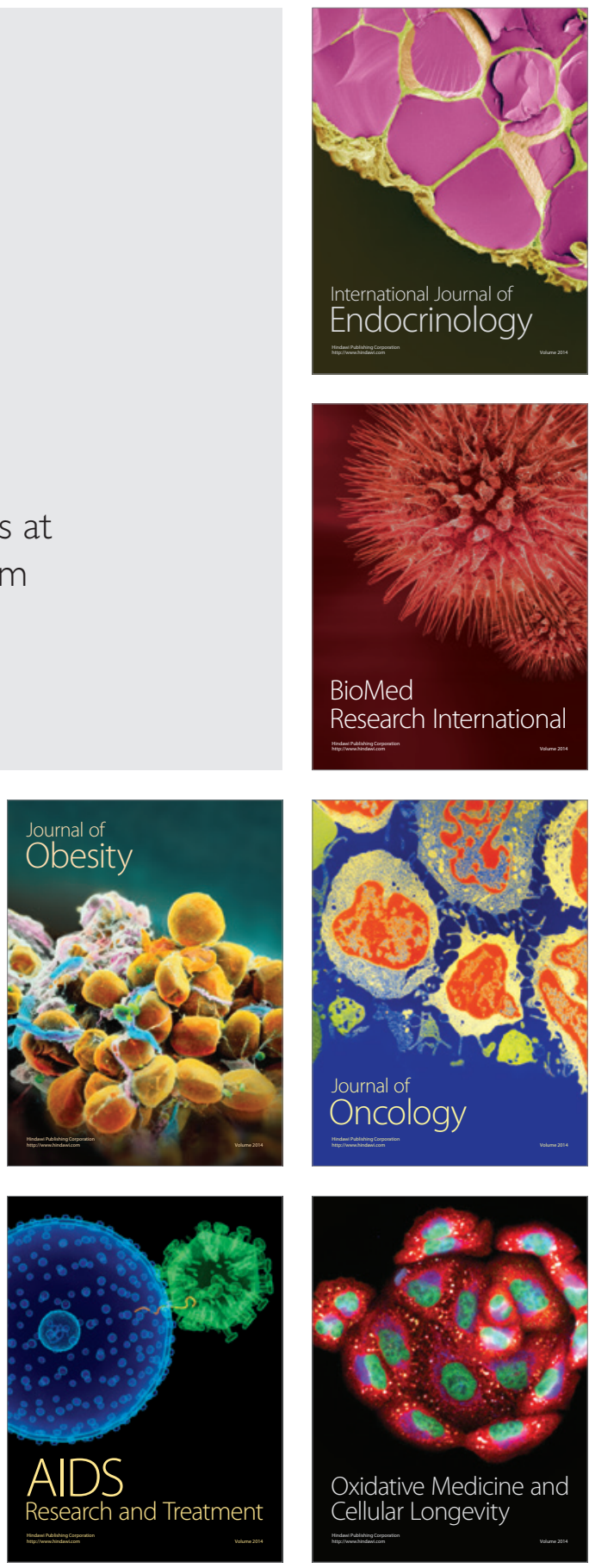